\title{
Smart contract: from definition to certainty
}

\section{$\Omega$ 目 Yuriy Truntsevsky}

Professor, Leading Researcher, Department of the Methodology of Counteracting Corruption, Institute of Legislation and Comparative Law under the Government of the Russian Federation, Doctor of Juridical Sciences. Address: 34 Bolshaya Cheremushkinskaya St., Moscow 117218, Russian Federation. E-mail: trunzev@yandex.ru

\section{$\Omega$ Vyacheslav Sevalnev}

Candidate of Juridical Sciences, Institute of Legislation and Comparative Law under the Government of the Russian Federation. Address: 34 Bolshaya Cheremushkinskaya St., Moscow 117218, Russian Federation. E-mail: sevalnev77@ gmail.com

\section{囲 Abstract}

The purpose of the present article is to gain an understanding of the opportunities and difficulties created by the introduction and development of the practice of network (smart) contracts. Our research methodology is based on a holistic set of principles and methods of scholarly analysis employed by modern legal science. It uses a dialectical method involving both general approaches (structural system method, formal logical method, analysis and synthesis of individual elements, individual features of concepts, abstraction, generalization, etc.) and particular methods (legal technical, systematic, comparative, historical, and grammatical methods, method of the unity of theory and practice, etc.). We analyze the views of lawyers and other specialists from Russia and abroad, legislative innovations in the field of digital technologies, the practice of blockchain-based smart contracts, and the main risks (whether legal, technological, operational, or criminogenic) of smart contracts for economic activities with a study of their causes. In the present-day situation, it is necessary to move from the legal definition of the smart contract and its legal and technological characteristics, advantages and disadvantages to the implementation of startups in a wide range of areas, especially business, public regulation, and social relations. Scholarly and information support for such processes will contribute to the development of industry, public administration and digital technology applications to improve the life of individual citizens and society as a whole. The introduction of smart contracts does not require the adoption of new laws or regulations. Instead, one should adapt and, possibly, modify existing legal principles at the legislative and judicial levels to pave the way for the use of smart contracts and other new technologies. The system of contract law provides a sufficient framework for regulating transactions without the introduction of any new legal categories. We propose approaches to the legal definition of the smart contract and identify a set of problems that must be solved at the legislative and technical legal levels in order to implement smart contracts effectively in different spheres of life. 


\section{O-1国 Keywords}

smart contract, blockchain, technology, contract law, risk, Internet of things, court.

Acknowledgments: The paper was written with support of the Russian Foundation for Basic Research (project no 18-29-16023).

For citation: Truntsevskyi Ju.V., Sevalnev V.V. (2021) Smart contract: from definition to certainty. Legal Issues in the Digital Age, no 1, pp. 100-122.

DOI: $10.17323 / 2713-2749.2021 .1 .100 .122$

\section{Introduction}

Network, or smart contracts (SC) have been attracting the keen interest of legal scholars and lawyers on account of their potential impact on contractual relations. The basic research problem in this domain is to study past practice and analyze obstacles to the introduction and improvement of SCs in Russia and other countries as well as to predict their future development and new spheres of application in the context of the exponential growth of digital technologies [Khabrieva T.Y., 2018: 5-16]; [Khabrieva T.Y., Chernogor N. N., 2018: 85-102].

SCs are indeed a revolutionary instrument. They can be used to decentralize many processes that people employ today and to improve existing solutions in a radical fashion. For example, E. Hughes ${ }^{1}$ has said that these technologies shall be brought by people who are sick and tired of government corruption and aggressive politics. At the same time, blockchains are still fraught with legal difficulties, and the law makes no mention of contracts based on this technology. There is a clear need to make a legal definition of this phenomenon.

In recent years, blockchains have fostered the emergence of SCs, which are being used at an ever greater rate [Perov V.A., 2017]; [Ivanov A.Y., 2017]. Speaking at the We Are Developers World Congress 2018 in Vienna, Apple co-founder S. Wozniak said that blockchains shall have an immense impact on the technology sector, calling them the "next major IT revolution that is about to happen." Programmers and lawyers should

${ }^{1}$ A US mathematician and programmer, one of the founders of the cyberpunk movement.

2 Available at: https://www.independent.co.uk/life-style/gadgets-and-tech/news/ bitcoin-steve-wozniak-blockchain-apple-cryptocurrency-revolution-a8357336.html (accessed: 2.08. 2019) 
cooperate on SC development. One needs dictionaries that connect legal language and computer code. Scholars must pool their efforts to develop technically advanced applications and powerful analytic tools.

SCs are attracting the keen interest of different industries due to their possible use in performing and automating certain actions in order to save time and money. There can be a lot of commercial benefit from using SCs for automatically calculating the payments due and the goods to be delivered by each party.

Possible domains for automating legal processes include operations such as due diligence, searching for clients, round-the-clock emailing and notification, document processing, model agreements, and other processes involving a high degree of regulation.

The introduction of SCs will lead to reduced paperwork and smaller, more frequent payments, improving cashflow while reducing potential problems thanks to more precise tracking and verification of the performance of contractual obligations. It will reduce human involvement and assure the total transparency of responsibilities and financial matters, making all economic sectors more accountable, transparent, effective and productive. "Smart documents" will make it possible to draft high-quality documents faster and more precisely, allowing lawyers to focus on fine details and negotiations between parties [Golovanova A.A. et al., 2019: 212]. Over the next five or ten years, "traditional" legal work should become increasingly automated [Anisimov V.F., Sergevnin V.A., 2018: 11-16].

The use of SCs poses interesting new questions in the domains of law and technology. Besides legal issues relating to the creation and use of SCs, there also exists the problem of their enforcement. In particular, one must determine which types of conflict resolution mechanisms can be used (or have to be created) and which types of legal remedies are or should be available in view of the immutable nature of the blockchain technology on which SCs are based.

Nevertheless, even if SCs are not legal contracts per se, they "are not in a legal vacuum," as Meyer and Eckert ${ }^{3}$ put it [Chandler S., 2019]. Even if the terms governing the relations between parties are not governed by law, SCs will still fall under national law or international agreements if they lead to such violations as drug trafficking. At the same time, SCs are associated

${ }^{3}$ Stephan Meyer and Martin Eckert are blockchain legal experts at the MME law firm in Zurich and Zug. Available at: https://finance.yahoo.com/news/smart-contracts-noproblem-world- 123200100.html (accessed: 2.08.2019) 
with a high level of legal risks that must be meticulously reduced in order to assure effective legal products and services.

Given the intersectoral and multidimensional nature of our subject, we conducted a comprehensive study of the following aspects of the problem:

Analyzing conceptual approaches to the legal regulation of FinTech and RegTech in Russia and abroad with regard to SCs;

Comparing the theoretical foundations, technical possibilities, and practical level of introduction and legal support of SCs;

Making a comparative legal analysis of the legal framework of SCs;

Analyzing the potential impact of digital technologies on law and society and on legislative activities aimed at reforming the economy and identifying economic sectors that require the introduction of SCs.

\section{Current Research}

SCs have received increasing attention in recent years due to their growing use, the adoption of official documents in the digital economy sphere, and the introduction of legal regulations. A search with the keyword "smart contract" on e-library.ru produced the following results (as of August 10, 2019):

This phrase figures in the titles of 152 publications, including 74 journal articles, 32 books, 65 conference proceedings, 2 reports, 2 patents, and 0 dissertations.

The number of publications with the phrase "smart contract" in their titles has the following chronology: 0 publications in 2016, 13 in 2017, 100 in 2018, and 39 during the first six months of 2019.

The phrase "smart contract" occurs 465 times in titles, abstracts and keywords ( 2 in 2016, 52 in 2017, 308 in 2018, and 103 during the first six months of 2019).

The content analysis of the use of the phrase "smart contract" shows that the first publications to mention SCs in Russia were papers by E. Popova, N. Popov and A. Zemtsov [Zemtsov A.N., 2016: 24-26]. In the citation impact, the articles by A. Savelyev [Savelyev A. I., 2017: 94-117] and E. Popova and N. Popov [Popova E.M., Popov N.V., 2016: 9-14] have been the most cited. Of the 20 publications with the greatest citation impact, 10 were devoted to legal matters, and the rest to technical, economic and managerial issues. 
Some scholars have conducted a legal analysis of SCs in the narrow sense, focusing on "the use of computer code for generating, verifying and executing agreements between parties"; the key legal issues here were notification, consent and protection of consumer rights' [Efimova L.G., Sizemova O. B., 2019: 23-30]; [Dolova M.O., 2019: 27-36]. Other authors have studied the problem from the standpoint of traditional civil law without isolating SCs from legal institutes [Kamalyan V.M., 2019: 20-27]; [Kalinina A.L., 2019: 37-45]; [Nagrodskaya V. B., 2019: 128]. Another group of scholars has written about the dual legal nature of SCs: they are technological solutions with a computer protocol that are not agreements, on the one hand, and agreements between parties in electronic form that have legal force, on the other [Shaidullina V.K., 2019: 21-23]. Finally, some practical specialists have examine possible conflict between SCs and theory of relational contracts [Gromova E. A., 2018: 34-37].

Many authors essentially recognize the fact that an SC is a type of computer code that can represent all, a few or one of the existing forms of contracts recognized by law [Nosov S. I., 2019: 6-13]; [Makarchuk N. V., 2019: 40-43]. Thus, even when the SC wholly refers to a legally binding agreement (often called a "smart legal contract"), it is still governed by contract law just as any agreement written in natural language.

As a result, most scholars believe that traditional contract law will continue to function in the age of SCs, and that the latter "will never fully replace the law of natural language." Nevertheless, they say that SCs may help to increase the clarity, predictability, verifiability and ease of enforcement of contractual relations. Unfortunately, no comprehensive scholarly study of the legal consequences of such contractual practices has appeared so far.

After collecting basic information about this new phenomenon, the aforementioned studies try to identify the areas in which these contracts differ from traditional contracts, examine whether SCs can be inscribed into the existing national legal framework, and recommend changes in contract law that would simplify their use and assure their legal effectiveness. They also attempt to answer such topical questions as "are SCs legally binding agreements?" and "will they replace traditional contracts?"

Studies of the legal problems connected with the introduction and use of SCs examine three different stages: contract generation and improvement; execution and modification; and violations and legal remedies thereto.

Foreign legal scholars have not been able to reach a consensus on the definition of SC, proposing many different approaches [Stark J., 2016]. 
This is not surprising given the nature of this new phenomenon and the complex technologies on which it is based. The simplest definition used in scholarly discussions is that the SC is an agreement between two or more parties that is coded in such a way that its correct implementation is guaranteed by a blockchain [Wattenhofer R., 2016]. Note that such a definition involves not only a digital contract between parties written in computer code but also a decentralized ledger (blockchain). This explains why a blockchain such as Ethereum is usually employed as the decentralized execution platforms that stores the SC [Bashir I., 2013].

At the same time, the SC has no need of a blockchain to function: no one can prevent the creation of SCs that are embedded into a traditional database. However, in this case, the parties would have to rely on a trustworthy centralized party, and the ledger would not be as immutable as in the case of a blockchain. As a result, such a contract would no longer be "smart," although it would be effective on account of the security that it provides thanks to its immutability and digital distribution among users.

As a rule, such legal studies end with the constatation that the SC conforms to the principles of contract law. Authors propose different legal remedies that can be applied to SCs and urge legislators and lawyers not to ignore their utility for assuring legal security.

\section{Legal regulation of the application of smart contracts}

The term "smart contract" does not figure in Russian legislative acts. Some normative legal acts have begun to mention this notion in recent years, however. For example, Order of the Russian Government no 2101-r "On approving a comprehensive plan for modernizing and expanding the trunk infrastructure up to the year 2024" of September 30, 2018, ${ }^{4}$ mentions that "the main cross-cutting data processing technologies in the transport industry that are planned for introduction during the implementation of the transport section of the plan include technologies of self-executing codes for performing obligations ('smart contracts')." Alongside the sections "Public report: national assessment of the risks of legalizing (laundering) criminal income. Main conclusions for 2017-2018" and "National assessment of the risks of financing terrorism: public report for 2017-2018,"5 Memorandum

${ }^{4}$ Sobraniye Zakonodatel'stva Rossiyskoy Federatsii. 2018. 42(II), \$6480 // SPS Consultant Plus.

5 Vestnik Banka Rossii. 2018, August 29. 
of the Bank of Russia IN-014-12/54 "On the national assessment of the risks of money laundering and financing terrorism" of August 14, 2018 includes the section "Transferring capital with the help of unregulated entities" whose item "Measures taken in the Russian Federation for managing risks" notes that "work is being conducted for making changes to Russian law so as to define and determine the status of digital technologies used in the financial sphere (including 'distributed ledger technology,' 'electronic letter of credit,' 'digital mortgage,' 'cryptocurrency,' 'token,' and 'smart contract')..."

The State Duma has adopted the laws "On amendments to the first, second and fourth parts of the Civil Code of the Russian Federation" 6 and "On attracting investments with the help of investment platforms and amending certain legislative acts of the Russian Federation," " which will enter into force on October 1, 2021; as a result, section 160, item 1, of the Russian Civil Code will define the SC as "an agreement employing electronic or other technical means" and relating to an agreement in written form. These regulations shall serve as the foundations for drafting a new law on digital financial assets (cryptocurrency and tokens). ${ }^{8}$

It should be said that Russian legislators are still looking for ways of juridically defining the legal status of SCs in different areas of economic activity and public governance, among others. To cite L. Cheng, founder of smart contract service provider Vanbex, "The legal world has yet to fully assimilate the new realities of technology, including smart contracts. So ultimately the answer to this question will lie in the individual legal processes in jurisdictions around the world" [Chandler S., 2019].

With regard to foreign experience in the legal regulation of SCs, 47 US states adopted the Uniform Electronic Transactions Act (UETA) in 1999, setting down rules for electronic contracts, records and signatures and affirming the validity of electronic contracts and of the use of electronic signatures for expressing consent to an agreement. Nevertheless, in 2017 some states decided to adopt supplementary rules in view of the large-scale use of SCs. Arizona passed laws that allow securing SC signatures through the blockchain technology. Vermont and Nevada recognize blockchainbased contracts as acceptable evidence for conflict resolution. Delaware permits the registration of shares of Delaware companies in blockchain

${ }^{6}$ SPS Consultant Plus.

7 SPS Consultant Plus.

${ }^{8}$ Federal bill 419059-7 "On digital financial assets" Adopted by the State Duma in first reading on May 22, 2018 // SPS Consultant Plus. 
form. Section 5 "Blockchain Technology" of Arizona law HB 2417 defines a smart contract as "an event-driven program that runs on a distributed, decentralized, shared and replicated ledger and that can take custody over and instruct transfer of assets on that ledger."

Western legal scholars [Gatteschi V. et al., 2018: 3] note that SCs have need of standardization: if different economic sectors continue to develop SCs in the absence of standards, companies will not derive full benefits from blockchain solutions. Such standards should assign responsibilities for SC development and operation and specify conflict resolution mechanisms, creating the presumption of the legal nature of SCs provided that they have certain properties and are used by market players in a certain way. This already exists in some domains: ISDA (International Swaps and Derivatives Association) provides master agreements for certain financial operations, while NVCA (National Venture Capital Association) is elaborating model legal documents for startups.

\section{Legal description of smart contracts (definition)}

Why are SCs "smart"? After all, they are neither artificial intelligence nor capable of machine learning. They only perform the actions they are instructed to perform.

Can they be called contracts? Courts have not ruled on this so far. Probably the answer to this question depends on the adoption of the "computer code is law" doctrine. Still, SCs - whether fully coded or in Ricardian form $^{9}$ - will most likely have to fulfill all the requirements of a legal contract to have legal force. A recent example of the use of SCs is Fizzy AXA. ${ }^{10}$ AXA is the first major insurance company to offer insurance policies based on blockchain (100\% automated, $100 \%$ safe platform of parametric insurance against flight delays): if a client's flight is more than two hours late, he or she automatically receives compensation for the delay; a delay of over two hours triggers the irrevocable action of transferring an automatic deposit that compensates for the client's losses.

9 In 1996, Ian Grigg and Gary Howland defined the Ricardian contract as a bridge between a textual contract and computer code that has the following features: (a) a contract offered by an issuer to holders, (b) for a valuable right held by holders and managed by the issuer, (c) easily readable (like a contract on paper), (d) readable by programs (parsable like a database), (e) digitally signed, (f) carrying the keys and server information, and (g) allied with a unique and secure identifier [Grigg I., 2004: 25-32].

10 Available at: https://www.axa.com/en/newsroom/news/axa-goes-blockchain-withfizzy (accessed: 2.08. 2019) 
Some foreign specialists [Navas Navarro S. et al., 2017] argue that SCs are neither ordinary contracts nor "smart" contracts and propose a different name - "program-executed transactions" - on the basis that they are not contracts but software. At the same time, the notion of "contract" is based on the desire of the parties to program its terms and values and, even more importantly, to create SCs as an alternative to traditional contracts.

Let us now take a closer look at SCs. There is a lot of rhetoric and propaganda about what they are or should be. Nevertheless, the reality is that SCs are software. They are coded in a state-of-the-art computer language such as Solidity. An SC is embedded in a blockchain and has access to its inner functions. At first sight, SCs may seem to be a clever idea that permits the infinite expansion of the basic technology of the "immutable distributed ledger" into which they are embedded and which considerably improves the flexibility of SCs and expands their areas of application.

A contract is typically an agreement between parties that must be executed by law. Contracts stipulate what each party must to do. Nevertheless, the development of the blockchain technology permits the automatic execution of contractual terms. This is made possible by the SC, which is a set of promises in code, including protocols through which the parties execute these promises.

Most legal contracts are based on templates that contain standardized legal formulations into which different terms can be inserted. These contracts mostly rely on third parties (courts, arbiters, guarantors, etc.) for their execution. This process is redundant and wastes a lot of time and money as well as being unpredictable. Yet all of this can be eliminated with the help of SCs that contain codes that can execute the terms of a contract automatically. The code of a contract defines its terms as a set of syllogisms in a similar way to a legal document.

Whereas an ordinary contract sets out the terms of mutual relations (that are legally binding, as a rule), a "smart" contract assures the respect of its terms with the help of cryptographic code. In other words, an SC is a program which, regardless of whether it is called a contract or not, allows the automatic execution of a contract that is either contained directly in the SC or associated with the SC, which serves as its compulsory execution mechanism coded in blockchain.

One typically cites the following characteristics of SCs [Savelyev A.I., 2016: 32]; [Ream J., 2016: 16]:

electronic nature;

software based on the "code is law" principle that will be created at the demand of the parties and subsequent subscribers. 
Higher reliability (certainty and accuracy). Whereas an ordinary contract, whether oral or written, is interpreted by human beings, the SC consists of computer code that is interpreted by computers. These codes have the advantage of being precise, so that all parties can predict the outcome of the contract. Such a contract is verifiable insofar as it is coded in blockchain and so has only one copy, incontestable evidence of its existence, and settled terms.

Conditionality. Computer codes follow the logic "if this, then that." The parties set down their terms with the help of a conditional statement that assures the execution of the contract.

Autonomy and independence: after the SC is agreed upon and launched, the execution of its codes takes place automatically without any special approval mechanism. Thus, the parties to the contract (and even third parties) are unable to stop this process even if they have second thoughts or make programming errors. For example, if a money transfer is arranged (e.g., scheduled for the first Sunday of each month over the next five years), then the transfer will take place on this specific day and in the initially specified amount over the next five years. This feature leads to the greater certainty of SCs.

Speed. The processes of preparing contracts and auxiliary documents are automated with the help of computer code rather than being drafted by hand. In addition, updates can be made in real time.

Lower cost. Money is saved insofar as less time is needed to fill out contracts, smaller wages are paid to employees to carry out such tasks, and future costs are reduced due to fewer errors and especially fewer intermediaries for verifying and executing contracts.

Security. SCs and their data are stored in a decentralized register which is secured with the help of cryptography. They cannot be lost, as each party has a copy, and are extremely difficult to hack. Even if a hacker manages to penetrate into the blockchain with the help of arbitrary addresses, he will be unable to access personal information.

New businesses and operational models. Such SC characteristics as lower costs, etc., create new opportunities. For example, electric cars can be charged by induction while standing on streets or at traffic lights with the help of SCs. ${ }^{11}$ The system known as the "Internet of Things" (IoT) connects

11 The world's first electric road that charges moving electric cars opens near Stockholm. Available at: https://fishki.net/2570200-pervaja-v-mire-jelektrificirovannaja-doroga-dlja-zarjadki-jelektromobilej-otkrylasy-v-shvecii.html (accessed: 2.08. 2019) 
computerized objects (for example, cars, kitchens, heart monitors, etc.) to the Internet in order to communicate data without any direct human involvement. The SC can execute its terms by interacting with digital objects.

SCs must be capable of automatically detecting events (if the event launches SC code and meets a pre-set criterion). For example, a rental car may be specially programmed to receive instructions connected to an SC and, if the debtor does not pay for the service, the car will not start [Tjong Tjin Tai E., 2017].

Can one amend SCs? This is a crucial question for the SC movement. The commonly held view is that there should be no return after the terms are set down in code, as automatic implementation and immutability are key features of SCs.

Nevertheless, this question should be answered for all types of SCs and especially for cases where SC execution can violate the law. Consider, say, an SC that specifies that the debtor must retain certain goods that could be confiscated by the creditor in 60 days. Some time later, the law is amended, and a new minimum delay of 120 days is set down. In this case, the contract was drafted correctly yet subsequently contradicted the law due to legislative changes. Would the SC continue to execute automatically, as initially agreed, and thus violate the law?

There are two possible ways of solving this problem: they may be called "public" and "private." In the first (ex ante ${ }^{12}$ ) approach, governmental agencies create a public database containing important regulations that can permit the SC to detect legal updates and update its terms. In the second (ex post ${ }^{13}$ ) approach, the state does not create such a database, letting the parties control the SC themselves. The disadvantage of such an approach is that parties can try to insist on the introduction of certain changes to further their own interests. To minimize this possibility, the contract should identify terms that can be changed (e.g., the fee) and the terms that cannot be changed under any circumstance (e.g., the contract deadline).

Thus, SCs are computer code that automatically executes terms set down by the parties for regulating their relations. The idea is to make the contract self-supporting, rendering its modification very complicated. If a conflict arises between the parties, the injured party will go to court only after the improper fulfillment or unjust enrichment, as the SC has already been or is being executed.

12 Ex ante refers to the modelling of future economic phenomena and processes.

${ }^{13}$ Ex post refers to actual results attained by the economy over a certain period. 
Although SCs are specially designed to avoid contract violations, they can be invalid if they lead to unlawful results, e.g., drug trafficking or selling alcohol to minors. The following actions may be taken to minimize these problems:

Writing computer codes in a precise manner and with variables that can be adapted to the law and its amendments. The parties should set down the terms in accordance with existing law and with the possibility of their future adaption to changes.

Explicitly prohibiting certain items in SCs (e.g., drugs), which requires (1) promulgating standards for the content of SCs (e.g., when selling expensive goods, a certain sum must be held on a special account to avoid violating tax rules, etc.), (2) embedding systems that detect violations of the law (e.g., when interest on a loan becomes usurious) or require identification to prove the lawfulness of a contract (e.g., the purchase of alcohol by minors).

Using not only SCs but also written contracts with an influence on the former for the purpose of minimizing discrepancies. In particular, people today still want to have contracts in hard-copy form that would be tangible and understandable to the average person. SCs could be used either to code terms that are not significant or exclusively to execute the terms of a written contract. In this case, one could adopt the proposal of the Russian Federal Tax Service to develop XML economic contracts.

If a textual version of the contract is also drafted.

The parties should discuss the possibility of distributing risks in the case of coding errors.

The textual agreement attached to the code should indicate the applicable law as well as determining the priorities of text and code in the event of a collision.

The textual agreement should include a statement by each party that it has seen the SC code and that the latter reflects the terms contained in the textual agreement.

The textual agreement can be submitted as evidence of the terms of the contract to a court.

When an ordinary contract is violated, the injured party brings an action to court for indemnity, specific execution or compensation for the inflicted damage. 
Thus, the SC should lead to the appearance of a new type of lawyer who will be a specialist in both law and computer science. In practice, programmers and lawyers are already cooperating on the solution of legal and technical issues. When lawyers create SCs, a team of professionals in the fields of law and technologies has to work together. Nevertheless, there is still a lot of room for innovation in this domain.

\section{Areas of application of smart contracts (certainty)}

It is easy to imagine how SCs could be applied in different industries and operations from wholesale deliveries to leasing equipment.

A more complicated task is to create SCs that can be used by companies. A number of enterprises are working on SC templates that companies could adapt to their needs. ${ }^{14}$ Slock is launching a program called "Alpha" that companies can use to integrate solutions for the sharing economy. Jincor is one of many enterprises working on templates that would meet legal norms and cryptocurrency standards. Companies can also hire programmers to create original SC solutions. This is a new domain, and so the offer is still quite limited. At the same time, companies must understand what processes they want to automate in their business with the help of SCs and calculate the savings that this automation would provide.

Thus, SCs have become a hot topic insofar as an ever greater number of applications are appearing in different industries (from the food industry and agriculture to financial services and insurance). SCs are attracting attention thanks to the opportunities they can provide: the distributed ledger technology should make SCs a better and more automated way of signing and executing contracts.

Although SCs are still relatively rare today, they can be used in virtually any scenario for transmitting and storing secure immutable data without intermediaries.

Here are a few examples.

Financing commerce. Today, commerce is often financed by banks for maintaining liquidity and raising trust in the exchange of assets. SCs can be used to facilitate the financing of commerce with the help of various data sets such as bills of lading, GPS and customs data. SCs can use such general control points for implementing full or partial payments, transferring

14 Available at: https://www.reuters.com/brandfeatures/venture-capital/ article?id=59712 (accessed: 2.08 .2019 ) 
property rights, and issuing reimbursements when the contractual terms are violated.

Healthcare. Public health computer systems store millions of medical records. Although healthcare organizations have invested enormous funds in security, current access and storage methods are a lot more vulnerable to cyberattack than their blockchain-based equivalents. Blockchain-based SCs can also be used to issue prescriptions, present bills, manage property, store test results, etc.

Medical studies. This industry produces important medical data, including test results and new drug formulas that must be kept secure and secret. They can be secured with the SC technology, which can also be used to communicate information to third parties for different reasons. This is only one example of how smart blockchain-based contracts can be beneficial for the medical research industry.

Property rights. SCs have two major areas of applications here. First of all, they can be used for registering property rights: the rapidity and low cost of SCs give them an advantage over existing systems in recording rights to all types of property from land and buildings to phones and watches. Secondly, the use of SCs on the real estate market can render the expensive services of lawyers and real estate agents superfluous. Instead, they will allow sellers to process transactions on their own.

Moreover, all intellectual property rights from royalties (from copyrights and trademarks, say) to patent licensing fees can be turned into SCs. Oracles can employ IP address databases for checking property rights and transferring payments from users to IP address owners. SCs can also be used to store information about the partial ownership of IPs and allocate the corresponding shares to persons.

Mortgages. SCs can also be used to make cheaper, quicker and more secure mortgage-based transactions. This will allow buyers to access purchased real estate more quickly as well as making the whole process smoother. "Smart" mortgage contracts will allow both sides to settle purchases in digital form before processing payments. As soon as this happens, information about property rights is updated in the SC to reflect the change of ownership. Insofar as the process requires the initial owner to input a unique key, it will be a lot more secure and less prone to fraud.

Insurance. The insurance industry spends tens of millions dollars annually to process claims. Moreover, it loses millions of dollars on account of fraudulent claims. 
In addition to providing support for creating insurance policies, SCs can be used to check for errors and calculate insurance payments on the basis of a set of criteria that reflect the insurance terms for an individual or corporate policyholder. Thus, faster processing, a drastic reduction in errors, and smaller expenses are among the key advantages of using SCs in insurance.

In the longer term, SCs can be used for IoT-based transport vehicles, making possible "pay on delivery" insurance policies and the immediate filing of claims after accidents. Such information as driver's licenses, car documents, and accident reports can be processed immediately in order to speed up payments, which will benefit both parties. Theft, accident and other claims can be filed automatically, guaranteeing rapid client compensation. The client's driving habits can also be used to calculate insurance premiums and make rebates. Useful data for developers include the respect of speed limits, mileage, car maintenance schedule, brake use, point of collision, and road quality.

Home insurance. The SC technology allows the connection of smart home appliances such as refrigerators, thermometers, stoves and alarm systems. Their IoT data may trigger automatic insurance payments for claims connected to fire, theft or property damage. Claims linked to weather or earthquakes can also be automatically checked and paid with the help of alarm systems, eliminating the cumbersome process of manual verification.

Medical insurance. Insurance companies can make use of developments in biotechnologies and IoT (smartwatches) to create SCs that would offer rebates on medical insurance or issue fines on the basis of information about the patient's health. Useful data include body weight, pulse, and possibly even more complex biometric information in the future. SCs can also be used to uncover anomalies that require medical consultations if the patient wants to continue to benefit from favorable rates.

Flight insurance. Web APIs such as Flight Stats and Aviation Edge provide minute-by-minute information about flight delays and cancellations. Programs such as Chainlink ${ }^{15}$ can update SCs on the status of flights to determine whether policyholders should receive compensation.

Insurance and reinsurance of large equipment. Many companies make use of large expensive equipment for their business operations. The

${ }^{15}$ Chainlink is the first decentralized oracle network that gives smart contracts decentralized bidirectional possibilities to receive external inputs and send outputs to other systems. Available at: https://blog.chain.link/44-ways-to-enhance-your-smart-contractwith-chainlink/ (accessed: 2.08. 2019) 
key mechanisms of such equipment can be provided with IoT devices for gathering real-time information about their state. Programs such as Chainlink can transmit such data to SCs for making insurance payments for failures or scheduled maintenance. As policies for large equipment are usually reinsured, Chainlink can be used to distribute claims and client payments between all insurance providers.

Supply chains (from procuring materials to delivering goods to the end user) are another business sector that can benefit from blockchain-based SCs. IoT devices can be used throughout the entire supply chain in order to record a product's every step. SC-based smart supply chains may theoretically eliminate internal theft, as managers will be able to track missing products to the precise time and place where they disappeared.

In large supply chains, SCs will allow managers to keep track of supplies in real time and calculate the time needed for products to pass through the whole chain. Managers will be able to use this information for adjusting supply levels and developing new working methods for accelerating deliveries.

For supply chains distributed across different places, SCs can be used to do all of the above as well as to initiate automatic reorders and payments of already received orders. The information contained in SCs can also be used for calculating future traffic in supply chains and even the products that should be stored in warehouses at different times of year.

Retail payments. Many popular user apps such as Uber and Airbnb allow clients to make retail payments with the help of SCs by giving the latter access to major credit cards and payment networks (PayPal and Stripe).

Public utility payments. Water, electricity and Internet may be called the foundations of modern society. Public utilities largely use outdated infrastructure and technologies for assuring security. SCs make it possible to modernize vital infrastructure by adapting and connecting outdated systems to blockchains.

Some public utilities such as Internet and cable TV collect regular lump-sum payments from their clients. However, when their services are disrupted, no one is held responsible. IoT devices can monitor the time of the faultless operation of public utilities, and programs such as Chainlink can input this data into SCs for calculating monthly payments or paying compensation for periods of inactivity.

IoT devices can also calculate the consumption of companies and individual users. Chainlink can incorporate consumption norms into SCs 
in order to initiate fines for excessive consumption, generate electricity bills, or collect carbon taxes. People can also sell their energy back to the Network for profit. SCs can record the readings of smart meters for monetizing output and facilitating payments for both energy consumers and producers. Solar panels, Tesla Powerwalls and wind turbines are examples of new energy sources that can be linked to SCs.

Waste management. Emissions and waste disposal are two sectors that can be transformed by SCs connected to IoT devices that make precise measurements of output volumes. Such data can automatically initiate payments to the respective regulatory body or monetize waste that is consumed during recycling or the conversion of waste to fuel.

Quality control. IoT devices can be used to verify the authenticity and proper maintenance of products over the whole supply chain. Examples include storing products at prescribed temperatures, verifying the hermeticity of containers, and tracking the location of goods. SCs can initiate payments and impose fines depending on whether the output of IoT devices confirms the respect of quality control standards as defined in the contract.

Voting and polls. ${ }^{16}$ Despite the use of computer systems costing millions of dollars, malfeasants still manage to rig voting results. SCs represent a simple and economically effective solution for assuring trust and transparency in this area. They can be used to confirm voters' identities and record their votes. This information can be used to trigger actions after voting results are tallied. As blockchain blocks cannot be changed after they are recorded, it is impossible to manipulate such results.

Personal data. SCs can also be used for biometric data such as fingerprints or eye scans. As biometric data are unique, they can provide an effective means of identifying people if there exists a reliable database or source for cross-referencing it. Oracles can deliver biometric data to SCs and connect the latter to different databases for authentication.

The concept of "decentralized identity" has been made possible by DLT apps. Personal data can be stored in a blockchain rather than in a public or private centralized repository. SCs can use such databases with the help of oracles for verifying registration data such as name and citizenship without leaking

${ }^{16}$ Opinion, a Russian-language social networking service, conducts polls and forecasts the outcomes of events with the help of "collective intelligence." Based on the EOS blockchain, the project was launched in early 2019 and has continued to develop ever since. For conducting polls, Opinion uses an SC that automatically records user responses in the blockchain. Available at: https://bits.media/oprosy-i-golosovaniya-na-blokcheyne-neizmennost-i-prozrachnost-rezultatov/ (accessed: 2.08.2019) 
personal information. In the future, such databases may be consulted by SCs for verifying voting results, checking KYC/AML, and passing customs.

In fact, the list of sectors that can benefit from the new technology is enormous. Given that SCs support and assure the secure development of products, these sectors can range from small startups to technology giants such as Microsoft or Amazon.

SCs can ultimately put an end to our dependence on banks. Another major benefit is that they can make our world more democratic. As they can be used for exchanging both simple things (e.g., labor) and more complicated entities (e.g., credits), the number of such services will undoubtedly grow exponentially over time.

\section{Risks of using smart contracts}

The technological advantages of SCs can help to speed up transactions, lower costs, and simplify and streamline processes. At the same time, it must be admitted that the use of the still developing SC and blockchain technologies is fraught with a number of potential risks, including risks of management, deployment and regulation, legal risks, and risk management.

The decentralized model creates problems for changing rules insofar as such changes must be agreed to by all parties for the SC to function. Moreover, things aren't as optimistic as they might seem: a Europol report ${ }^{17}$ suggests that terrorists, who receive the bulk of their financing through ordinary money transfers today, may begin to use SCs for organizing attacks and other illicit activities in upcoming years.

The reliability of SCs also evokes doubts. Fraudulent schemes and financial pyramids are already being organized with the help of SCs. Some key drawbacks of the introduction of SCs include

The early phase of development of SCs and blockchains turns away individual consumers, companies and governmental agencies. The complexity of these technologies and their associated risks make people suspicious insofar as they are accustomed to writing hard-copy documents setting down the rights and responsibilities of parties and signing them by hand.

Uncertain regulatory framework: it is not yet clear how SCs will be governed by law. For this reason, their recognition by courts could have

17 Terroristy i smart-kontrakty. Evropol vypustil trevozhny otchet [Terrorists and smart contracts: Europol publishes an alarming report]. Available at: https://www.rbc.ru/ crypto/news/5ba3aa4a9a794711b661ebdd (accessed: 2.08. 2019) 
a decisive impact on the development of apps that would help to avoid undesirable legal consequences.

Errors: if the computer code does not precisely match the parties' intent or simply contains programming errors, the system might not execute as expected.

Rigidity: the basic idea is to agree on conditions that would be automatically implemented. However, the parties must foresee future scenarios that may require changes.

Rather than being eliminated, third parties will begin to play new roles. For example, experienced lawyers will consult clients on creating new contracts.

Our analysis of the potential risks of introducing SCs into economic and other social relations points to the existence of the following groups and types of risks:

legal risks (legal indeterminacy, contradictory or insufficient court precedents, etc.);

technological risks (peculiarities of software, etc.);

operational risks (role of the human factor (personnel) in applying computer technologies, etc.);

criminogenic risks (use of SC technologies for embezzlement and other crimes).

\section{Conclusion}

It is important to pass from the legal definition of SCs, the description of their legal and technological aspects, and the enumeration of their advantages and disadvantages to the creation of startups in a wide range of areas, including business, state control, and social relations. Research and informational support for the theoretical and practical results of such processes shall promote the development of diverse sectors of the economy, public governance and digital technologies and improve the quality of life of citizens and society as a whole.

To be effective, SCs and blockchains require a set of standards or general rules for all participants in order to assure accuracy and precision. Blockchain management standards will ultimately strengthen market confidence in these technologies and their regulatory framework. This will accelerate the diffusion and success of SCs.

To sum up, blockchain-based SCs aim to change the way contracts function. Many companies and governments are working on these tech- 
nologies in view of the advantages they can provide (lowering costs, raising security, increasing speed and, of course, confidence). However, key drawbacks inhibiting their broad use include their early development phase and especially the ambiguity of whether they shall be governed by existing laws or require additional regulations. For the time being, these technologies shall be limited to certain business sectors such as banking and insurance rather than being used by private individuals. We believe that SCs shall not replace traditional contracts: rather, they will provide some sectors with alternatives that can give considerable benefits.

Current approaches to the legal regulation of SCs are in keeping with existing principles of contract law. They provide a number of legal and technical remedies and encourage legislators and lawyers not to overlook SCs as useful tools for assuring legal security. SCs are self-executing contracts that, in a certain sense, can be viewed as spinoffs of electronic data exchange. Their automatic execution is often implemented through computer code that translates legal language into a self-executing program that exercises control over relevant material and digital objects. SCs may be called sets of programmable computer functions that can self-execute upon the fulfillment of certain conditions.

Thus, a decentralized blockchain-based SC is a digital agreement that (a) is written in computer code (software), (b) runs on blockchains or similar distributed ledger technologies (decentralized), and (c) executes automatically without the need for human interference ("smart").

There are two approaches to legally defining the SC. One is to call it a type of contract. Such a contract becomes legitimate, it is protected by existing law, and the SC (code) can be used as electronic evidence. The other is to view the SC not as a separate type of contract but as a means of formatting an agreement between economic actors using the blockchain technology in order to save time and technical and material assets and to lower or eliminate legal risks for the parties. To this end, one can use either a wait-and-see approach or a "sandbox" for regulating SCs and the blockchain technology as a whole. The blockchain space is constantly developing and altering course in an unpredictable manner so that one should be wary about regulating things that have not been fully understood so far.

The following initiatives are necessary for developing a legal framework for SCs:

studying the legal consequences of the discovery of an intentional error in translating contract terms into computer code: will they differ from the consequences of unintentional errors? 
enforcing the execution of automatic terms - in particular, through enforcement or bankruptcy proceedings;

studying the possibility of publishing an official list of contract types that can contain self-executing terms;

prohibiting contracts requiring state registration from containing selfexecuting terms;

assigning responsibilities to parties for errors in the computer code and introducing procedures for mitigating the consequences of errors, hacker attacks, and force majeure (in particular, by the decision of the court) and protecting from fraud, blackmail and other unlawful intentions (by recognizing an agreement as void and applying the consequences of invalidity);

solving the problem of presenting documents with contract terms to courts, tax authorities and other public agencies.

Developing a mechanism for demonstrating the unambiguous consent of the contractual parties to the terms of the SC and for assuring courts that these parties had been sufficiently informed about the contractual terms. There are two possible approaches to this issue: stakeholders should either develop SCs to bring them into line with existing law or develop new laws that would address the legal fine points of SCs. The use of closed key cryptographic signatures as a means of "signing" SCs should be considered objective proof of acceptance, intention and mutual agreement simultaneously.

Internet courts should recognize submitted digital data as evidence (recognition of digital objects as new types of evidence) if the parties collect and store this data on a blockchain with digital signatures and reliable time tags or on a digital platform and can prove the authenticity of the employed technologies. In some cases, it may be necessary to conduct technical expert evaluations or recruit specialists who would prove that an entry in the register was indeed made by a specific person at a specific time. Evidence that is authenticated and presented with the help of blockchains should be considered admissible in legal cases.

\section{国国 References}

Anisimov V.F., Sergevnin V.A. (2018) Robotics and automation: legal education and profession. Yuridicheskoye obrazovaniye i nauka, no 3, pp. 11-16 (in Russian)

Bashir I. (2017). Mastering blockchain. Birmingham: Packt, 531 p.

Chandler S. (2019) Smart contracts are no problem for the world's legal systems, so long as they behave like legal contracts. Available at: 
https://cointelegraph.com/news/smart-contracts-are-no-problem-forthe-worlds-legal-systems-so-long-as-they-behave-like-legal-contracts (accessed: 10.06.2020)

Dolova M.O. (2019) The question of applicability of blockchain technology in the consideration of cases by courts. In: Yu. V. Truntsevsky (ed.) Legal regulation of contractual relations arising in connection with development of digital technologies (smart contracts). Round table proceedings. Moscow: Jurist, pp. 27-36 (in Russian)

Efimova L.G., Sizemova O.B. (2019) Legal nature of the smart contract. Bankovskoye pravo, no 1, pp. 23-30 (in Russian)

Gatteschi V. et al (2018) Blockchain and smart contracts for insurance: Is the technology mature enough? Future Internet, no 10, p. 20.

Golovanova N.A., Gravina A.A., Zaitsev O.A. (2019) Criminal activity in the conditions of digitalization. Moscow: Kontrakt, 212 p. (in Russian)

Grigg I. (2004) The Ricardian contract. In: Proceedings of the First IEEE International Workshop on Electronic Contracting, pp. 25-31.

Gromova E.A. (2018) Smart contracts in Russia: an attempt to determine their legal essence. Pravo i tsifrovaya ekonomika, no 2, pp. 34-37 (in Russian)

Ivanov A.Y. et al. (2017) Blockchain at the peak of HYIP: legal risks and opportunities. Moscow: Higher School of Economics Publishing House, 237 p. (in Russian)

Kalinina A.L. (2019) Issues of using smart contracts. In: Legal regulation of contractual relations arising in connection with development of digital technologies (smart contracts). Round table proceedings, pp. 37-45 (in Russian)

Kamalyan V.M. (2019) Concept and legal features of smart contracts. Yurist, no 4, pp. 20-27 (in Russian)

Khabrieva T.Y., Chernogor N.N. (2018) Law in the conditions of digital reality. Zhurnal rossiyskogo prava, no 1, pp. 85-102 (in Russian)

Khabrieva T.Y. (2018) Law before the challenge of digital reality. Zhurnal rossiyskogo prava, no 9, pp. 5-16 (in Russian)

Makarchuk N.V. (2019) Public law restrictions on the use of digital assets and technologies. Predprinimatel'skoye pravo, no 1, pp. 40-43 (in Russian) Nagrodskaya V.B. (2019) New technologies (blockchain / artificial intelligence) at the service of law. Moscow: Prospekt, 128 p. (in Russian)

Navarro N. et al (2017) Inteligencia artificial. Valencia: Tirant, 293 p.

Nosov S.I. (2019) Law and informatization. Yurist, no 4, pp. 6-13 (in Russian) 
Parfenov A.V., Shapovalov I.M., Valko D.V., Kirillov A.A. (2015) Logistics of e-commerce. Saint Petersburg: State Economic University, 79 p. (in Russian)

Perov V.A. (2017) Identification, qualification and organization of investigation of crimes committed with the use of cryptocurrency. Moscow: Yurlitinform, 177 p. (in Russian)

Popova E.M., Popov N.V. (2016) Blockchain as a driver of change in the banking sector]. Bankovskiye uslugi, no 12, pp. 9-14 (in Russian)

Rassolov I.M., Matytsina T.V., Yanenko M.B. (2006) Legal issues of Internet relations. Moscow: Yuniti, 165 p. (in Russian)

Ream J., ChuY., Schatsky D. (2016) Upgrading blockchains: Smart contract use cases in industry. Deloitte University Press, no 4, pp. 1-11.

Savelyev A.I. (2016) Contract law 2.0: "Smart" contracts as the beginning of the end of classical contract law. Vestnik grazhdanskogo prava, no 3, pp. 32-60 (in Russian)

Savelyev A.I. (2017) Some legal aspects of using smart contracts and blockchain technologies under Russian law. Zakon, no 5, pp. 94-117 (in Russian)

Shaidullina V.K. (2019) Smart contracts on the financial market: research results. Sud'ya, no 2, pp. 21-23 (in Russian)

Sinitsyn S.A. (2019) The agreement: new aspects of legal regulation and interpretation. Zhurnal rossiyskogo prava, no 1, pp. 45-61 (in Russian)

Stark J. (2016) Making sense of blockchain smart contracts. Available at: https://www.coindesk.com/making-sense-smart-contracts/ (accessed: 20.05.2018)

Tjong Tjin Tai E. (2017) Formalizing contract law for smart contracts. Available at: https://ssrn.com/abstract=3038800 (accessed: 20.05 .2018 )

Volos A.A. (2018) Smart contracts and principles of civil law. Rossiyskaya yustitsiya, no 12, pp. 5-7 (in Russian)

Wattenhofer R. (2016) The science of the blockchain. Create Space Independent Publishing Platform, $131 \mathrm{p}$.

Yanenko M.B., Yanenko M.E. (2015) Methodology of elaborating marketing strategies in the conditions of using information and digital technologies. Saint Petersburg: State Economic University, pp. (in Russian)

Zemtsov A.N. (2016) Blockchain for all. Otkrytye sistemy, no 4, pp. 2426 (in Russian) 